\title{
ЭФФЕКТИВНОСТЬ И СПЕЦИФИКА ИСПОЛЬЗОВАНИЯ ГИС МТ «ЧЕСТНЫЙ ЗНАК» В БОРЬБЕ С НЕЗАКОННЫМ ОБОРОТОМ ТОВАРОВ
}

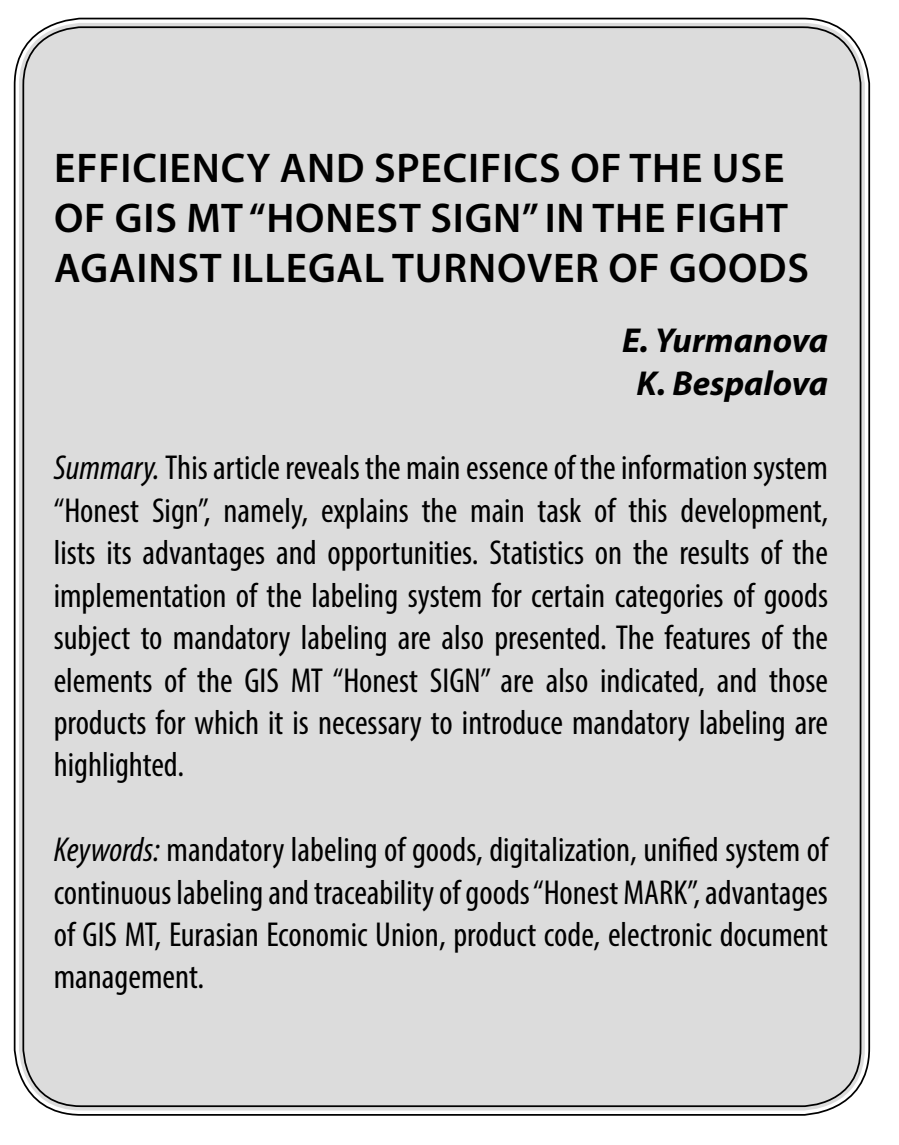

$\mathbf{M}$ ишустиным Михаилом Владимировичем 6 февраля 2021 года была утверждена Стратегия, которая направлена на целенаправленную борьбу с нелегальным оборотом промышленной продукции на территории Российской Федерации. Данный документ включает перечень тех мер, которые необходимо реализовать до 2025 года. Что касается обязательной маркировки товаров средствами идентификации, то Стратегия включает такие меры, как:

1. Дальнейшее развитие и усовершенствование государственной информационной системы прослеживаемости товаров на всех этапах движения [2];

2. Постепенное введение системы обязательной маркировки как на территории РФ, так и на уровне государств - членов Евразийского экономического союза (далее - ЕАЭС);

3. Увеличение списка маркируемой продукции на категории тех товаров, которые подлежат обя-
Юрманова Елена Александровна

Дочент, ФГБОУ ВО «Саратовский государственный технический университет имени Гагарина Ю.А.», 2. Саратов

yurmanova.elena@yandex.ru

Беспалова Кристина Валерьевна ФГБОУ ВО «Саратовский государственный технический университет имени Гагарина Ю.А.»,

2. Саратов

kristina.bespalova98@mail.ru

Аннотация. В данной статье раскрывается основная суть информационной системы «Честный ЗНАК», а именно поясняется главная задача данной разработки, перечисляются её преимущества и возможности. Представлена также статистика результатов внедрения системы маркировки по отдельным категориям товаров, подлежащих обязательной маркировке. Также обозначены особенности элементов ГИС МТ «Честный ЗНАК», и выделены те товары, в отношении которых нужно ввести обязательную маркировку.

Ключевые слова: обязательная маркировка товаров, цифровизация, единая система сплошной маркировки и прослеживаемости товаров «Честный ЗНАК», преимущества ГИС МТ, Евразийский экономический союз, код товара, электронный документооборот.

зательной маркировке средствами идентификации.

В декабре 2017 года Президент России одобрил создание единой системы сплошной маркировки и прослеживаемости товаров. Оператором системы распоряжением Правительства РФ назначен центр развития перспективных технологий (далее - ООО «Оператор ЦРПТ»), а координатором работы по введению маркировки в России определено Минпромторг России.

Доля незаконного оборота товаров на территории РФ крайне высока. Данная проблема наглядно изображена на диаграмме 1.

Чтобы обезопасить покупателей от такой продукции, в России в 2018 году была создана единая национальная система цифровой маркировки и прослеживаемости товаров «Честный ЗНАК». Главная задача данной разра- 


\title{
Доля нелегальной продукции, \%
}

\author{
Товары лёгкой промышленности $₫$ Обувь \\ - Парфюмерия = Шабачные изделия
}

Лекарственные препараты

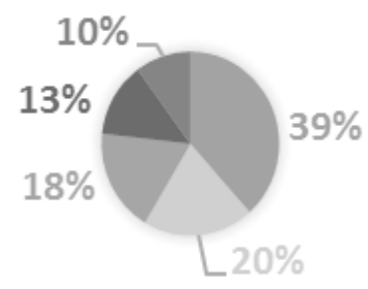

Диаграмма 1. Доля нелегальной продукции в\%-ом соотношении

ботки заключается в увеличении степени безопасности государства, бизнеса и граждан посредством борьбы с контрабандой, контрафактом и фальсификатом [4].

В системе зарегистрировано более 500000 компаний, отслеживается порядка 29 млрд. кодов товаров. Теперь необходимо разобраться как работает данная система. На заводе производитель наносит код DataMatrix на товар. Другими словами, такой код является цифровым паспортом товара. Далее все участники торговой цепочки сканируют код на товаре и передают информацию о нём в систему. Что немаловажно, каждый код защищён криптографией. Его практически невозможно подделать, скопировать или похитить.

История обязательной маркировки началась ещё в 2016 году, когда на уровне ЕАЭС было принято решение о необходимости проведения эксперимента по маркировке меховых изделий. Рынок меховых изделий живёт в своём времени, он не особо цифровой и не самый мобильный. Огромный объем товарооборота в тот момент времени находился в сером поле. Это удручало не только органов государственной власти, но и честных игроков рынка. В 2016 году рынок был переполнен нелегальной продукцией, поэтому в тот период необходимо было упорядочить оборот товаров на территории стран - членов ЕАЭС, минимизировать ущерб от незаконного оборота, а также упростить контроль и надзор за перемещаемыми товарами.

На отрасль меховых изделий было дано менее полугода для того, чтобы подготовиться к проекту по внедрению обязательной маркировке на данную категорию товаров. Как сообщают представители компании «Снежная Королева», новая система позволила не только упростить логистические процессы, но и упорядочить взаимодействие с государственными органами и ведомствами. Вследствие введения обязательной маркировки в отношении товаров из меховых изделий подорожали цены на изделия у тех компаний, которые работали в нелегальном поле. Нечестные участники рынка начали платить налоги. Только за первый год, когда была введена обязательная маркировка, из теневого оборота вышло более 25 -ти\% продавцов меховых изделий. Сотрудниками Роспотребнадзора было конфисковано порядка 11000 шуб на общую стоимость более 600 млн. руб.

В настоящее время «Честный ЗНАК» контролирует такие категории товаров, как табачные изделия, изделия из натурального меха, обувь, лекарственные препараты для медицинского применения, фотоаппараты и лампы - вспышки, шины и покрышки, духи и туалетную воду, некоторые товары лёгкой промышленности, ювелирные украшения, а также некоторые продукты группы молочной продукции [3]. В таблице 1 приводится список тех товаров, в отношении которых необходимо ввести обязательную маркировку. Дело в том, что те товары, которые приведены в таблице 1, могут принести вред здоровью и жизни человека, поскольку контакт с ними происходит постоянно.

На стадии эксперимента сейчас находятся кресла - коляски, предназначенные для реабилитации., велосипеды и велосипедные рамы., упакованная питьевая вода. Что касается пива и пивных напитков, то эксперимент по данной категории будет проводиться с 1 апреля 2021 года по 31 августа 2022 года.

Также в соответствии с поручением Президента РФ по подготовке проведения эксперимента по маркировке пива и слабоалкогольной продукции в данном случае сам механизм маркировки должен стать не только 
Таблица 1. Обязательная маркировка товаров

\section{Товары, в отношении которых необходимо ввести обязатель- ную маркировку}

1. Наполнители матрасов, содержащие полибромированные дифениловые эфиры (ПБДЭ)

2. Ручные и автоматические освежители воздуха

3. Косметические средства по уходу за телом

4. Антиперспиранты различного типа

5. Сотовые и мобильные телефоны

6. Ноутбуки, планшеты, персональные компьютеры

7. Ультрафиолетовые и инфракрасные обогреватели

8. Посуда с антипригарным покрытием

10. Контейнеры для консервированных продуктов, содержащих бисфенолы

\section{Причина, по которой необходимо введение такой меры}

ПБДЭ, являясь летучим соединением, могут попадать в организм человека через дыхательную систему и нанести вред щитовидной железе, мозговым тканям и репродуктивной половой системе.

Содержат такие опасные химические вещества, как эфиры этиленгликоля

и парадинхлорбензола. При частом использовании освежителей в помещениях, которые плохо проветриваются или вовсе являются закрытыми, есть риски попадания вышеперечисленных веществ в организм человека через дыхательную систему с последующим поражением жизненно важных органов.

Каждая женщина, которая привыкла ежедневно наносить по 10 кремов на свою кожу, даже не задумывается о том, какой вред она наносит своему организму. Ведь далеко не все вещества прописываются в составе косметических средств.

Например, парабены, которые встречаются практически во всех косметических средствах, могут привести к раку молочных желез. Тот же бензил пероксид, который помогает бороться с черными точками, также при чрезмерном нанесении на кожу может вызвать усугубление опухоли в сторону её роста.

К сожалению, пока ещё нет абсолютной уверенности в том, что вещества, содержащиеся в данной продукции, совершенно безвредны. Многие учёные до конца не могут понять могут ли антиперспиранты нанести вред здоровью и жизни человека. Но для того, чтобы потребитель, который приобретает товар, был уверен в безопасности веществ, входящих в состав продукции, необходимо нанести обязательную маркировку. Потребитель с помощью приложения получит информацию о товаре, где самым ключевым моментом будет производитель и состав с процентным содержанием веществ.

Всем известно влияние телефонов на организм человека. Не раз слышали о том, что радиочастотные волны плохо сказываются как на общем самочувствии человека, так и отрицательно влияют на функции некоторых органов, приводя к различным расстройствам со стороны нервной и репродуктивной систем. Такие устройства содержат опасные вещества, а именно ртуть, кадмий и мышьяк. В свою очередь, вещества могут вызвать рак, различные кожные заболевания и дисфункции со стороны иммунитета.

Экраны и системные блоки товаров данной категории опасны электромагнитным излучением. Такого рода излучение в основном воздействует на сердечно - сосудистую систему, мозговую активность и зрение. В обязательной маркировке должна быть обязательно указана приблизительная степень излучения.

Одни учёные говорят о пользе двух названных обогревателей, другие больше склоняются к вреду от использования. Дело в том, что чрезмерное использование любого обогревателя может нанести существенный вред организму. Электромагнитные волны могут вызвать заболевания со стороны зрения, кожи, мышц и даже кровеносной системы.

Когда во время приготовления еды необходимо прибавить газ, та же сковорода начинает выделять в окружающую среду крайне токсичный газ. Человек, вдыхая его, повреждает тем самым органы дыхания и все обменные процессы в организме.

Всем хорошо известно, что при распылении специальных веществ для борьбы с насекомыми никто не должен оставаться в помещении. Вся проблема в том, что многие не соблюдают требования, которые прописаны на этикетках товаров, поэтому вещества, содержащиеся в данных спреях, наносят достаточно большой ущерб организму в целом. Инсектициды способны за достаточно короткое время вызвать неврологические нарушения как у детей, так и у взрослого человека.

Специальные консервные банки для продуктов содержит такого рода опасное химическое вещество, как бисфенол. Опасен он для людей, которые склонны к диабету и заболеваниям сердечно - сосудистой системы. Многие производители давно не используют данное вещество в производстве контейнеров для хранения консервированных продуктов. Но сама проблема в том, что не известно несут ли полную безопасность те вещества, которые заменили бисфенол. 

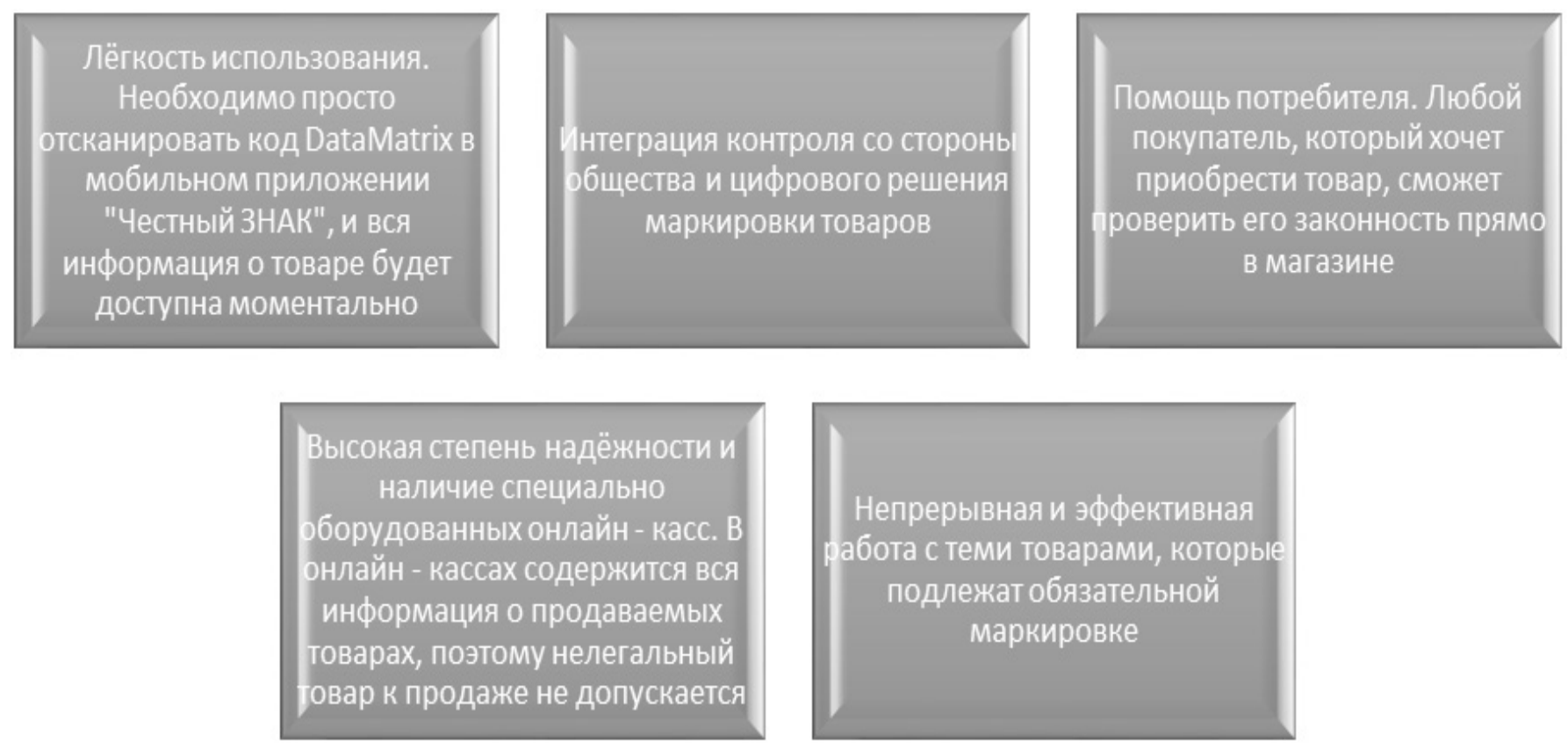

Схема 1. Преимущества использования ГИС МТ «Честный ЗНАК».

инструментом противодействия незаконному обороту данной категории товаров, но и той точкой роста, которая позволит всем бенифициарам этого процесса — государству, бизнесу и потребителям найти возможности по улучшению и увидеть преимущества, которые несет цифровизация в данной сфере.

Чтобы система маркировки осуществляла свою деятельность наиболее эффективно, было принято решение об объединении государственной информационной системы маркировки товаров «Честный ЗНАК» (далее ГИС МТ «Честный ЗНАК») с информационными системами других органов государственной власти и иных структур, которые также участвуют в осуществлении контроля и надзора за обязательной маркировкой товаров на территории РФ.

Ряд систем были разработаны и в предшествующие годы. Часть из них были закрыты. Сегодня среди работающих систем можно перечислить систему ЕГАИС - эта система предназначена для контроля оборота алкогольной продукции. Система ГИС «Меркурий», которая осуществляет обеспечение оборота продукции, подлежащей ветеринарному контролю. Существует система голографической маркировки цифровой аудиовизуальной продукции и другие системы.

ГИС МТ «Честный ЗНАК» осуществляет свою работу по принципу честности [5]. В первую очередь, это честность перед самими потребителями как основными участниками оборота товаров. Речь идёт о прозрачно- сти всех процессов, происходящих с товарами - от момента создания и вводом в оборот до вывода из оборота. Основные преимущества использования данной ГИС МТ показаны на схеме 1.

Минпромторг России как координатор по введению маркировки совместно с ООО «Оператор - ЦРПТ» создал беспрецендентно открытые и прозрачные условия для обсуждения в отраслях вопросов по вводимой маркировке. К обсуждению приглашались не только участники рынка, а именно представители бизнеса, производители товаров, проводящие цепочку, но и представители общественных организаций, союзов, представители науки, эксперты. Учитывалось каждое мнение, просчитывался каждый шаг, все риски. Стояла самая главная цель - не навредить, учесть все разумные пожелания участников рынка. Этот момент был очень важный, поэтому работа с отраслями и полными товарными группами будет проходить в дальнейшем также внимательно, также будут учитываться все пожелания отраслей бизнеса.

Проект по созданию ГИС МТ развивался с наднационального уровня. Как и было отмечено ранее, он был заложен ещё в 2016 году. В первые же месяцы был зафиксирован большой вклад данного инструмента в обеление рынка.

Более $20 \%$ участников оборота, ранее не подававших сведения в соответствующие ведомства, не представляющие сведения в налоговый орган, легализовали свой 
бизнес. В соответствии с реальными объемами рынка, которые зафиксировала система маркировки, было принято решение о дальнейшем расширении и развитии перечня маркируемой продукции. В первую очередь акцент делался на товары, которые наиболее чувствительны к незаконному обороту. Сам проект развивался достаточно ускоренными темпами, и уже сейчас можно сказать о том, что маркируется значительный перечень товаров широкого потребительского спроса.

В настоящее время виден положительный эффект, который показывает данный проект посредством влияния на экономическую, социальную сферу жизни нашего государства. Удалось выявить работу так называемых «Черных фармацевтов», которые в Московском регионе осуществляли реализацию льготных препаратов для терапии ВИЧ и онкологических заболеваний, предназначенные для льготных пациентов и должны были выдаваться в других регионах РФ.

По табачной продукции также был зафиксирован значительный эффект, который говорит о том, что в системе зарегистрировались новые производители порядка 10-ти компаний, ранее не подававшие соответствующие сведения о товарах в ведомства. Речь идёт о тех компаниях, которые долгое время находились в тени. По исследованиям экспертных организаций доля нелегальной продукции на табачном рынке в 2020 году снизилась до 10,5\%. В 2019 году такой показатель составлял $16 \%$. За достаточно долголетний период впервые наблюдается снижение темпов роста незаконного оборота табачной продукции в части сигарет и папирос.

Участники товаропотока вводят в оборот значительные количества обувных товаров, маркируя их, отображая все необходимые действия в системе. Первоначально эксперты оценивали объем рынка обуви в 450 млн. пар. Однако с начала 2020 года в оборот уже было введено более 1 млрд. единиц обувной продукции, включая остатки. И в ближайшее время, осуществляя мониторинг по данному направлению, мы, как участники оборота товаров, сможем оценить реальные объемы обувной продукции в РФ.

Конечно же, в части эффекта для государства - это противодействие незаконному обороту, а также увеличение собираемости соответствующих обязательных налогов, таможенных платежей, возможность повысить эффективность доверяющих организаций, контрольно-надзорных ведомств в части повышения эффективности работы сотрудников и упрощения их деятельности, потому что на каждую единицу продукции, которая подлежит обязательной маркировке, наносится соответствующее средство идентификации. Весь жизненный путь товара прослеживается, и все сведения о нём находятся в информационной системе.

Дополнительно установлено то, что участники оборота, являющиеся производителями продукции, могут получать информацию о своей продукции, которая находится в обороте. Данная возможность закреплена в Постановлении Правительства от 31 декабря 2019 № 1955 [1]. Помимо данных, переданных участником в систему, помимо общедоступных сведений, производитель может получат информацию о своем товаре в части его количества и владельца. Данный вопрос в настоящее время прорабатывается Минпромторгом России совместно с бизнес-сообществом. Согласовываются объемы и порядок предоставления этих данных для того, чтобы производители получали ту информацию, которая позволит воспользоваться в рамках хозяйствующей деятельности данными организациями. В настоящее время прорабатывается пилотный проект совместно с ФТС и Роспатентом по защите бренда, так называемый проект, с помощью которого будет понятно, как именно правообладатели смогут воспользоваться механизмом маркировки по защите своей собственной продукции и прав владельцем бренда.

Для потребителей необходимо отметить, что преимуществом введения системы маркировки является инструмент общественного контроля, который заключается в возможности защитить собственные права как потребителей. Граждане могут, не отходя от кассы, в самом магазине отсканировать с помощью приложения «Честный ЗНАК» само средство идентификации и получить всю необходимую информацию о приобретаемом товаре. При обнаружении нарушения гражданин может подать соответствующую жалобу. Сами приложение было скачано уже более 2,5 млн. раз. С помощью мобильного приложения было проверено уже более 32 млн. товаров. Более всего проверке подвергалась обувная продукция - более 16 млн. раз. Лекарства препараты для медицинского применения проверялись более 6 млн. раз.

Сама цифровизация внедрения в деятельность бизнеса электронного документооборота призвана в будущем сократить издержки на соответствующие процессы, связанные с логистикой и внутренним учетом, оптимизировать работу компаний и, конечно же, данная работа направлена на обеление рынка и возможность добросовестным участникам рынка нарастить собственную долю после ухода с него незаконопослушных конкурентов. То есть стоит цель избавиться от ситуаций с искажённой конкуренцией.

В целом сам новый подход к возможности прослеживаемости продукции повышает эффективность контрольно-надзорных органов и позволяет не усиливать 
контрольную нагрузку на самих предпринимателей, а также предоставляет возможность действовать в режиме онлайн, то есть в режиме реального времени с использованием риск-ориентированного подхода.

Повышение цифровизации торговли и экономики, а также цифровизации деятельности участников рынка и сам проект маркировки не является отдельным существующим в инфраструктуре РФ. Он связан со многими другими проектами, в том числе с внедрением контрольно-кассовой техники.

Дальнейшее развитие столь инновационного проекта связан с большой проводимой работой не только контролирующих органов государственной власти и ведомств, но и предпринимательским, отраслевым и экспертным сообществом.

Сам проект не имеет аналогов по своему охвату и спектр маркируемой продукции постепенно расширяется. До 2025 году планируется охватить весь перечень промышленной продукции. В настоящее время прорабатывается новая группа товаров для запуска соответствующих экспериментов. Каждый этап товарооборота в соответствии правилами маркировки, которые утверждаются Постановлениями Правительства, прослеживается в ГИС МТ «Честный ЗНАК» — это призвано облегчить войну правообладателей с недобросовестными участниками рынка. Именно поэтому в настоящее время данный вопрос находится в высокой степени проработки.

Учитывая масштаб и размеры нашей страны, ключевое направление по работе не только Минпромторга России, но и ООО «Оператор - ЦРПТ» в соответствии с поручением Заместителя Председателя Правительства Григоренко Дмитрия Юрьевича был сформирован в каждом субъекте РФ оперативный штаб - рабочая группа по контролю за информацией в части введения системы маркировки. Хочется отметить, что в настоящее время в ГИС МТ «Честный ЗНАК» зарегистрировано порядка семи тысяч республиканских компаний. Между национальными операторами России и Белоруссии организован информационный обмен, и сейчас производители Республики Беларусь могут получать коды идентификации через информационную систему ГИС МТ от оператора России и сразу наносить на товар.

На еженедельной основе происходит заседание, которое проводит Минпромторг РФ при участии ООО «Оператор - ЦРПТ», а также руководителей и членов данных рабочих субъектов РФ, где заслушиваются ситуации о готовности участников оборота товаров, подлежащих маркировке к введению новых требований. Заслушиваются также основные вопросы и разбираются кейсы, с которыми сталкиваются регионы в своей деятельности по повы- шению информированности бизнес-сообщества в субъектах, также рассматриваются возникающие вопросы, которые задают представители бизнеса, транслируя через соответствующие ведомства. Дополнительно проводятся серии вебинаров, обучающих семинаров посредством видео - конференций со всеми субъектами РФ и со всеми представителями бизнес-сообществ, которые ведут свою деятельность на территории всего государства. Информация направляется в субъекты РФ, а также размещается на официальном сайте оператора системы маркировки.

Данная система маркировки в РФ в действительности самая уникальная в мире не только с точки зрения покрытия, но и с точки зрения возможностей. Система маркировки сама по себе не является чем-то, что победит нелегальную торговлю, но она является тем, что поможет — это инструмент, который поможет выделять и разделять четко легально это или нет.

Любое перемещение товара сопровождается электронным документооборотом, в котором содержится информация о том, кто являлся первым собственником, кто купил товар, все это оформляется электронной накладной, а затем прикладываются коды. Именно вся эта информация содержится в одном коде. Электронный документооборот способствует оптимизации логистики посредством оформления электронных счет - фактур и договоров. Все это дает влияние на экологические вещи, то есть помогает уйти от использования бумаги, предупредить и оптимизировать производство, не использовав воду и электричество в больших объёмах.

Все производители, которые стараются бороться с нелегальным оборотом продукции и пытаются её защитить, тратят огромное количество денежных средств на то, чтобы создать свою систему контроля посредством сформирования веб-сайтов.

Система маркировки фактически является триггером для развития и роста других индустрий. Например, разработка и использование электронных рецептов для врачей является очень важным прорывом в сфере медицины. Врач всего лишь говорит пациенту код лекарства, который нужно приобрести в аптеке. Последний идёт в ближайшую аптеку, произносит код и получает необходимые лекарства. Что немаловажно, в условиях пандемии производители лекарств могут в режиме реального времени видеть, где и какие лекарства находятся и куда их нужно срочно отправить или перевезти.

Помимо ГИС МТ «Честный ЗНАК» запущена более расширенная информационная система «Честный ЗНАК. Гос», пользоваться которой могут только сотрудники государственных органов. На данный момент с разработанным нововведением работают сотрудники Роспо- 
требнадзора, а уже далее оно будет использоваться теми службами, которые будут определены в соответствии с Постановлениями Правительства. В информационную систему «Честный ЗНАК.Гос» можно зайти только по специальным доступам, поскольку она является государственной системой, и в ней содержится информация, которая является строго конфиденциальной.

Но существует и проблемы, которые могут возникнуть в отношении информационных систем. Дело в том, что системы маркировки товаров могут быть выведены из строя из-за хакерских атак. В этом случае штриховые коды будут в силу невозможности прекращения товарооборота беспрепятственно реализоваться с нелегальными товарами. В Республике Беларусь для безопасности маркировки более чем двух десятков товарных групп используются контрольно-идентификационные знаки, а сами товары находятся под защитой голографических нанотехнологий, а именно ноу-хау, голограммой, которая содержит скрытые изображения.

\section{ЛИТЕРАТУРА}

1. Постановление Правительства РФ от 31 декабря 2019 года № 1955 «0б обеспечении доступа к информации, содержащейся в государственной информационной системе мониторинга за оборотом товаров, подлежащих обязательной маркировке средствами идентификации» [Электронный ресурс] URL: https://www.garant.ru/products/ipo/prime/doc/73267439/ (Дата обращения: 03.03.2021)

2. Распоряжение Правительства РФ от 6 февраля 2021 года № 256-р «06 утверждении Стратегии по противодействию незаконному обороту промышленной продукции в РФ на период до 2025 года» [Электронный ресурс] URL: https://www.garant.ru/products/ipo/prime/doc/400224356/ (Дата обращения: 01.03.2021)

3. Распоряжение Правительства РФ от 28 апреля 2018 года № 792-р «0б утверждении перечня отдельных групп товаров, подлежащих обязательной маркировке средствами идентификации» [Электронный ресурс] URL: https://www.garant.ru/products/ipo/prime/doc/71834112/ (Дата 06ращения: 03.03.2021)

4. Особенности системы «Честный 3НAK».—URL: https://честныйзнак.рф/ (Дата обращения: 03.03.2021)

5. Система цифровой маркировки и прослеживаемости товаров.— URL: https://minpromtorg.gov.ru/activities/markirovka/ (Дата обращения: 04.03.2021)

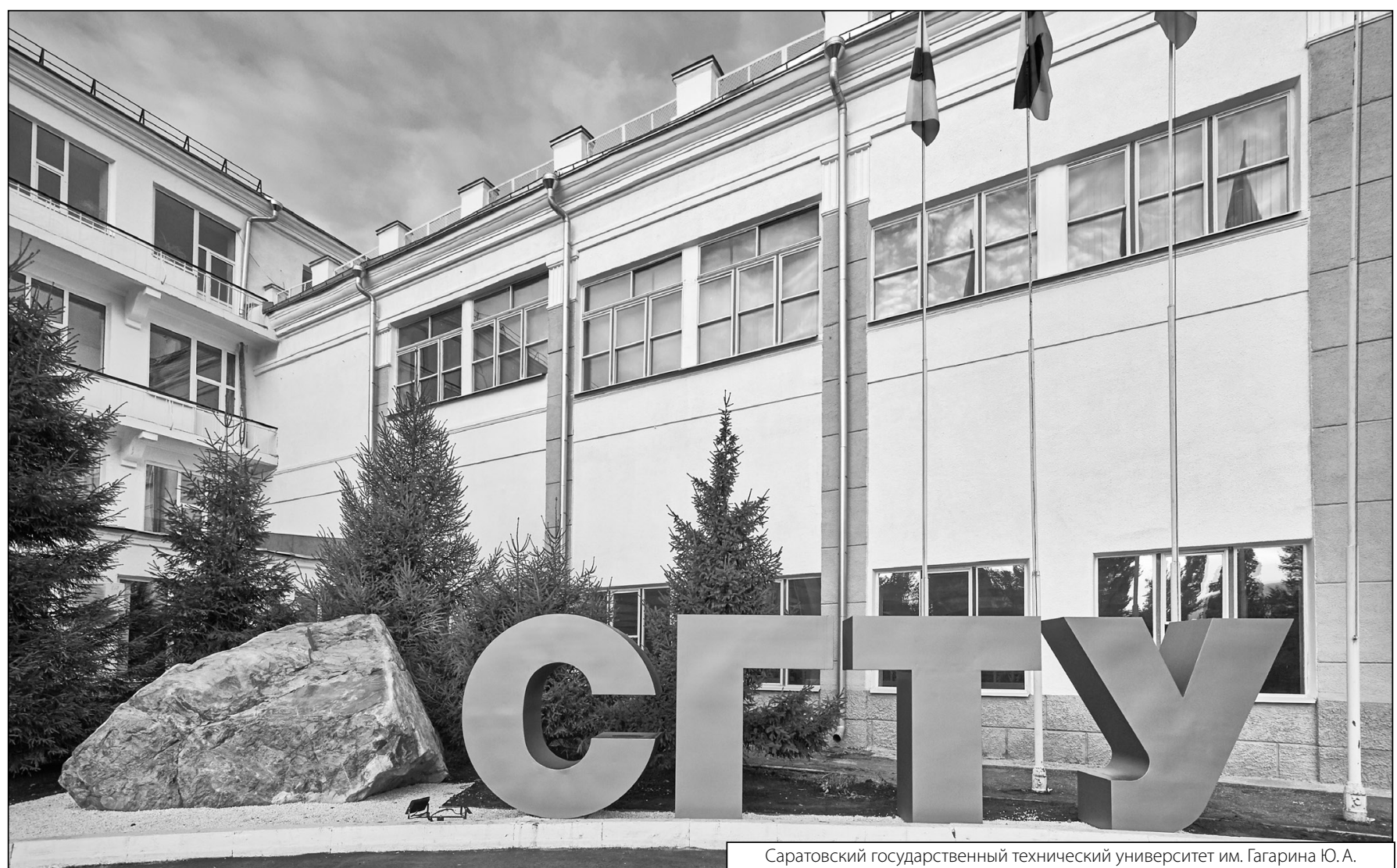

